University of Nebraska - Lincoln

DigitalCommons@University of Nebraska - Lincoln

2009

\title{
Evaluation of Revalor-IH and Revalor-IS as Initial Implants Compared with Traditional Initial Implants for Finishing Heifers and Steers
}

J. D. Folmer

University of Nebraska-Lincoln

T. B. Farran

University of Nebraska-Lincoln

G. E. Erickson

University of Nebraska-Lincoln, gerickson4@unl.edu

T. J. Klopfenstein

University of Nebraska-Lincoln, tklopfenstein1@unl.edu

C. D. Reinhardt

Kansas State University, Manhattan

See next page for additional authors

Follow this and additional works at: https://digitalcommons.unl.edu/animalscifacpub

Part of the Animal Sciences Commons

Folmer, J. D.; Farran, T. B.; Erickson, G. E.; Klopfenstein, T. J.; Reinhardt, C. D.; Dicke, B. D.; Drouillard, J. S.; Streeter, M. N.; and Vasconcelos, J. T., "Evaluation of Revalor-IH and Revalor-IS as Initial Implants Compared with Traditional Initial Implants for Finishing Heifers and Steers" (2009). Faculty Papers and Publications in Animal Science. 761.

https://digitalcommons.unl.edu/animalscifacpub/761

This Article is brought to you for free and open access by the Animal Science Department at DigitalCommons@University of Nebraska - Lincoln. It has been accepted for inclusion in Faculty Papers and Publications in Animal Science by an authorized administrator of DigitalCommons@University of Nebraska - Lincoln. 


\section{Authors}

J. D. Folmer, T. B. Farran, G. E. Erickson, T. J. Klopfenstein, C. D. Reinhardt, B. D. Dicke, J. S. Drouillard, M. N. Streeter, and J. T. Vasconcelos 


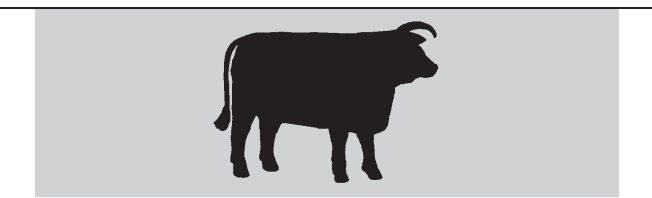

E

valuation of Revalor-IH and Revalor-IS as Initial Implants Compared with Traditional Initial Implants for Finishing Heifers and Steers ${ }^{1}$

\author{
J. D. Folmer, ${ }^{\star}$ T. B. Farran, ${ }^{*}$ G. E. Erickson, ${ }^{\star}$ PAS, T. J. Klopfenstein, ${ }^{*}$ C. D. Reinhardt, $†$ PAS, \\ B. D. Dicke,‡ PAS, J. S. Drouillard,† M. N. Streeter,§ and J. T. Vasconcelos, ${ }^{\star}{ }^{2}$ PAS \\ *Department of Animal Science, University of Nebraska, Lincoln 68583; †Department of Animal \\ Science, Kansas State University, Manhattan 66506; ‡Cattlemens Nutrition Services, Lincoln, NE \\ 68516; §Intervet/Schering Plough Animal Health, DeSoto, KS 66018; and \#Panhandle Research \\ and Extension Center, University of Nebraska, Scottsbluff 69361
}

\begin{abstract}
Two commercial feedlot experiments were conducted to compare performance and carcass characteristics of feedlot heifers and steers using 2 implant strategies. In Exp. 1, heifers ( $n=1,124$; initial $B W=279 \pm 5 \mathrm{~kg}$ ) were administered either Revalor-IH [Intervet/ Schering Plough Animal Health, DeSoto, $K S$; $8 \mathrm{mg}$ of estradiol (E2) and $80 \mathrm{mg}$ of trenbolone acetate (TA)] or Synovex- $H$ (Fort Dodge Animal Health, Overland Park, KS; $20 \mathrm{mg}$ of estradiol benzoate and $200 \mathrm{mg}$ of testosterone propionate) at initial processing, with both treatment groups receiving Revalor-200 (20 mg E2 and $200 \mathrm{mg}$ TA) as the common terminal implant $81 d$ (range 69 to $85 d$ ) before

\footnotetext{
${ }^{1}$ A contribution of the University of Nebraska Agricultural Research Division, Lincoln, Nebraska. Journal Series No. 14570. This research was supported in part by funds provided through the Hatch Act.

${ }^{2}$ Corresponding author: jvasconcelos2@unl.
} edu
\end{abstract}

slaughter. In Exp. 2, steers ( $n=1,066$; initial $B W=269 \pm 2 \mathrm{~kg}$ ) were administered either Revalor-IS (16 mg E2 and $80 \mathrm{mg}$ TA) or Synovex-S (Fort Dodge Animal Health; $20 \mathrm{mg}$ estradiol benzoate and $200 \mathrm{mg}$ progesterone) at initial processing, with both treatment groups receiving Revalor-S (24 $\mathrm{mg}$ E2 and 120 mg TA) as a common terminal implant an average of $78 d$ (range 71 to $84 d$ ) before slaughter. Implanting heifers initially with Revalor-IH improved G:F (P $=0.01)$ and $A D G(P=0.05)$ compared with heifers implanted initially with Synovex-H. In addition, Revalor-IH implanted heifers tended to have greater ( $P$ $=0.07)$ marbling scores, and 58\% more carcasses $(P=0.02)$ achieved the upper two-thirds Choice category with no differences observed in USDA YG. Implanting steers initially with Revalor-IS tended to increase hot carcass weight $(P=0.07)$ and carcass-adjusted final $B W(P=$ 0.07) compared with steers implanted initially with Synovex-S. However, implanting steers initially with Revalor-IS had no effect on performance or carcass characteristics compared with an initial implant of Synovex-S. Overall, moderatedose E2-TA initial implants can improve both $G: F$ and marbling scores in heifers. In steers, moderate-dose E2-TA initial implants may improve hot carcass weight and carcass-adjusted final $B W$ but may have no impact on carcass characteristics.

Key words: carcass quality, cattle, feedlot, implant

\section{INTRODUCTION}

Growth-promoting implants have been proven as safe and effective management tools in feedlot cattle production. Implants increase growth rate, improve feed conversion, and increase final BW of cattle by as much as 14 to $42 \mathrm{~kg}$ compared with nonimplanted cattle (Guiroy et al., 2002). These improvements in growth are largely the result of increased 
muscle deposition (NRC, 1996). This increase in growth rate and lean deposition may occur at the expense of carcass quality (i.e., reduction in marbling score) if implanted cattle are marketed at weights comparable with nonimplanted cattle, which suggests that to achieve comparable QG, implanted cattle should be fed to greater BW and similar body composition (Preston et al., 1990; Guiroy et al., 2002).

Determining proper implant strategy (number of days exposed and dosage, or combination of dosages) is an important consideration relative to QG. Several commercial anabolic implants are available to optimize carcass value (Montgomery et al., 2001). These implants contain a single dose or a combination dose of compounds. Different responses to implants have been attributed to the total amount of an anabolic agent (Bartle et al., 1992). Moderate-dose initial implant combinations of estradiol-17 $\beta$ (E2) and trenbolone acetate (TA) are available for heifers and steers and may have different effects on animal performance and carcass quality when compared with estrogen-based initial implants. Hutcheson et al. (2003) observed that a combination of E2 and TA implants, used in either the full or reduced dosage form, improved ADG, G:F, and hot carcass weight (HCW) while maintaining carcass quality in short-fed yearling steers when compared with an estrogen-based implant.

The objective of the present study was to evaluate the effects of 2 moderate-dose implants (Revalor-IH and Revalor-IS; Intervet/Schering Plough Animal Health, DeSoto, KS) relative to estrogen-based initial implants on animal performance and carcass characteristics of feedlot heifers and steers.

\section{MATERIALS AND METHODS}

\section{Experiment 1}

Beef heifers (British cross; initial $\mathrm{BW}=279 \pm 5 \mathrm{~kg}$ ) were received at a commercial feedlot in central Nebraska and at initial processing were

\begin{tabular}{|c|c|c|}
\hline Item & $\begin{array}{c}\text { Exp. } \\
1^{1}\end{array}$ & $\begin{array}{c}\text { Exp. } \\
2^{2}\end{array}$ \\
\hline \multicolumn{3}{|c|}{ Ingredient, \% (DM basis) } \\
\hline Steam-flaked corn & 61.3 & 62.3 \\
\hline Dry-rolled corn & 10.5 & 10.6 \\
\hline $\begin{array}{l}\text { Wet distillers grains } \\
\text { with solubles }\end{array}$ & 10.0 & 9.0 \\
\hline Alfalfa hay & 7.5 & 3.0 \\
\hline Mixed hay & - & 4.0 \\
\hline Liquid supplement & 5.0 & 5.0 \\
\hline Corn steep liquor & 3.0 & 3.5 \\
\hline Tallow & 2.7 & 2.6 \\
\hline \multicolumn{3}{|l|}{$\begin{array}{l}\text { Formulated nutrient } \\
\text { composition, }{ }^{3} \%\end{array}$} \\
\hline $\mathrm{CP}$ & 13.9 & 14.6 \\
\hline $\mathrm{Ca}$ & 0.7 & 0.7 \\
\hline$P$ & 0.3 & 0.4 \\
\hline
\end{tabular}

${ }^{1}$ Exp. 1 with heifers; diet provided $0.4 \mathrm{mg} / \mathrm{d}$ per head melengesterol acetate.

${ }^{2}$ Exp. 2 with steers.

${ }^{3}$ Formulated to contain $33 \mathrm{~g} / \mathrm{t}$ Rumensin (monensin; Elanco Animal Health, Greenfield, IN) and $11 \mathrm{~g} / \mathrm{t}$ Tylan (tylosin; Elanco Animal Health; DM basis).

allotted randomly to 1 of 2 implant regimens (within $72 \mathrm{~h}$ after arrival). Each group of incoming cattle represented a treatment replication, for a total of 6 replications per treatment (12 pens total; 1,124 heifers). Heifers were kept separate by arrival date and assigned randomly to pens by sorting every other animal as it exited the processing chute during initial processing. Within a replication, all heifers were from the same source and arrived at the feedlot at the same time. At initial processing, heifers were individually weighed, vaccinated with Bovishield 4 (Pfizer Animal Health; New York, NY), treated for internal and external parasites with Dectomax (Pfizer Animal Health), palpated for previous ear implants (implants were removed if present), and given a lot tag for pen identification and individual animal identification number. Initial implant treatment was either Revalor-IH (8 mg
E2 and $80 \mathrm{mg}$ TA; Intervet/Schering Plough Animal Health) or Synovex-H (20 mg estradiol benzoate, $200 \mathrm{mg}$ testosterone propionate; Fort Dodge Animal Health, Overland Park, KS). After processing, pens of heifers were weighed on a group scale just before being moved into their home pen. The pen BW was used as the initial BW for performance calculations. The total number of animals in a pen ranged from 80 to 120 head, and was equal within replicates. After arrival and processing, one complete replicate was removed from the study because of excessive morbidity.

Heifers were fed a common steamflaked, corn-based finishing diet twice daily throughout the study (Table 1). Cattle were adapted to the finishing diet over an 18- to 21-d step-up period beginning with $45 \%$ roughage that was progressively replaced with corn. The finishing diet also provided 0.4 $\mathrm{mg}$ /heifer daily of melengesterol acetate (MGA; Pfizer Animal Health), $33 \mathrm{~g} /$ ton Rumensin (monensin; Elanco Animal Health, Greenfield, IN), and $11 \mathrm{~g} / \mathrm{t}$ Tylan (tylosin; Elanco Animal Health), all on a $100 \%$ DM basis.

All heifers were reimplanted with Revalor-200 (20 mg E2 and $200 \mathrm{mg}$ $\mathrm{TA}$ ) as the common terminal implant $81 \mathrm{~d}$ (range 69 to $85 \mathrm{~d}$ ) before slaughter. At reimplantation time, heifers were removed from their pens and immediately weighed on a group scale to obtain a pen BW. Heifers were then revaccinated with Bovishield 4 (Pfizer Animal Health), individually weighed, and reimplanted before being sent back to their home pen for the remainder of the feeding period. Initial implants also were evaluated at this time to identify defects, including abscessed, bunched, missing, crushed, partial, or cartilage-placed implants. Heifers were fed an average of $177 \mathrm{~d}$ (range 147 to $202 \mathrm{~d}$ ). All pens within a replication were marketed on the same day under identical conditions at the same commercial abattoir (Tyson Fresh Meats Inc., Lexington, NE). Hot carcass weights were recorded on the day of harvest. Carcass 12th-rib fat thickness, LM area, and USDA called QG and YG were recorded 
Table 2. Results of implants checked before terminal implanting ${ }^{1}$

Exp. $1^{2}$

\begin{tabular}{lccccc}
\cline { 2 - 3 } \cline { 5 - 6 } Item & Revalor-IS & Synovex-S & & Revalor-IS & Synovex-S \\
\hline Abscessed & 3 & 5 & & 1 & 3 \\
Bunched & 1 & 0 & & 1 & 2 \\
Missing & 4 & 5 & & 3 & 3 \\
Partial & 0 & 0 & & 2 & 5 \\
Separated & 0 & 0 & & 5 & 2 \\
Placed within cartilage & 1 & 2 & & 1 & 0 \\
Total, n & 9 & 12 & & 13 & 15 \\
Percent defective implants & 1.6 & 2.2 & & 2.5 & 2.8 \\
\hline
\end{tabular}

Exp. $2^{3}$

${ }^{1}$ Values represent number of heifers (Exp. 1) or steers (Exp. 2) found with defective implants.

${ }^{2}$ Conducted at reimplantation time (d 81, range 69 to 85 d) on 553 heifers initially administered either Revalor-IH or 551 heifers administered Synovex-H (Fort Dodge Animal Health, Overland Park, KS).

${ }^{3}$ Conducted at reimplant time ( $\mathrm{d} 77$, range 71 to $84 \mathrm{~d}$ ) on 524 steers initially administered either Revalor-IS (Intervet/Schering Plough Animal Health, DeSoto, KS) or 525 steers administered Synovex-S (Fort Dodge Animal Health). cessing, pens were treated as in Exp. 1 and resulted in 12 pens, ranging from 70 to 120 head. Group BW were taken after processing and used as initial pen BW for the study.

Steers in Exp. 2 were fed similarly to Exp. 1, with the exception of the removal of MGA from the supplement. Steers were also fed a steamflaked corn-based finishing diet with $33 \mathrm{~g} / \mathrm{t}$ Rumensin (monensin; Elanco Animal Health) and $11 \mathrm{~g} / \mathrm{t}$ Tylan (tylosin; Elanco Animal Health) on a DM basis (Table 1). Replications of steers in Exp. 2 were reimplanted in a manner similar to those described in Exp. 1. Revalor-S (24 mg E2 and $120 \mathrm{mg}$ TA) was administered as the common terminal implant an average of $78 \mathrm{~d}$ (range 71 to $84 \mathrm{~d}$ ) before slaughter. Steers were revaccinated with Titanium 3 (Intervet/Schering Plough Animal Health), poured with Cylence (Bayer Animal Health, Kansas City, MO), individually weighed, and reimplanted. Steers were fed for an average of $180 \mathrm{~d}$ (range 170 to 191 d). In Exp. 2, all pens within a rep- after a 24-h chill. Empty body fat was calculated from the equations of Guiroy et al. (2002), where empty body fat $=17.76207+(4.68142 \times$ fat thickness, cm $)+(0.01945 \times \mathrm{HCW}$, $\mathrm{kg})+(0.81855 \times \mathrm{QG})-(0.06754$ $\times$ LM area, $\left.\mathrm{cm}^{2}\right)$. Calculated YG was estimated with the formula from American Meat Science Association (2001), where $\mathrm{YG}=2.5+(6.35 \times$ fat thickness, $\mathrm{cm})+(0.2 \times \% \mathrm{KPH})$ $+(0.0017 \times \mathrm{HCW}, \mathrm{kg})-(2.06 \times$ LM area, $\mathrm{cm}^{2}$ ). Marbling score was recorded on a scale as follows: $450=$ Slight ${ }^{50} ; 500=$ Small $^{0} ; 550=$ Small $^{50}$; $600=$ Modest $^{0}$.

\section{Experiment 2}

Beef steers (British cross; initial $\mathrm{BW}=269 \pm 2 \mathrm{~kg}$ ) were received as in Exp. 1, resulting in 6 replications per treatment (1,077 steers). At initial processing, steers were individually weighed, vaccinated with Titanium 5 (Intervet/Schering Plough Animal Health), treated for internal and external parasites with Dectomax (Pfizer Animal Health), palpated for previous ear implants (implants were removed if present), and given a tag for individual and pen identification. Initial implant treatment was either
Revalor-IS (16 mg E2 and $80 \mathrm{mg}$ TA) or Synovex-S (20 mg estradiol benzoate and $200 \mathrm{mg}$ progesterone; Fort Dodge Animal Health). After pro-
Table 3. Effects of Revalor-IH or Synovex-H as initial implants on feedlot heifer performance (Exp. 1)

\begin{tabular}{lcccc} 
& \multicolumn{2}{c}{ Initial implant ${ }^{1}$} & & \\
\cline { 2 - 3 } Item & Revalor-lH & Synovex-H & SEM & P-value \\
\hline Number of pens & 6 & 6 & - & - \\
Number of heifers & 535 & 546 & - & - \\
Initial BW, kg & 279 & 279 & 5 & 0.99 \\
DMI, kg & 8.7 & 8.7 & 0.2 & 0.63 \\
Carcass performance & & & & \\
Final BW, ${ }^{2}$ kg & 570 & 564 & 3 & 0.15 \\
ADG, ${ }^{3}$ kg & 1.66 & 1.62 & 0.05 & 0.10 \\
G:F ${ }^{3}$ & 0.190 & 0.186 & 0.001 & 0.03 \\
Live performance & & & & \\
Final BW, ${ }^{4}$ kg & 550 & 542 & 3 & 0.09 \\
ADG, ${ }^{5}$ kg & 1.54 & 1.49 & 0.04 & 0.05 \\
G:F ${ }^{5}$ & 0.178 & 0.172 & 0.001 & 0.01 \\
\hline
\end{tabular}

${ }^{1}$ All heifers implanted with Revalor-200 (Intervet/Schering Plough Animal Health, DeSoto, KS) as the common terminal implant. Revalor-IH was from Intervet/Schering Plough Animal Health (DeSoto, KS), and Synovex-H was from Fort Dodge Animal Health (Overland Park, KS).

${ }^{2}$ Calculated as hot carcass weight $\div 0.63$ (common dressing percentage).

${ }^{3}$ Calculated using carcass-adjusted final BW.

${ }^{4}$ Calculated from live pen BW and shrunk $4 \%$.

${ }^{5}$ Calculated from live final BW. 


\section{Table 4. Effects of Revalor-IH or Synovex-H as initial implants on carcass characteristics of finishing heifers (Exp. 1)}

\begin{tabular}{|c|c|c|c|c|}
\hline \multirow[b]{2}{*}{ Item } & \multicolumn{2}{|c|}{ Initial implant ${ }^{1}$} & \multirow[b]{2}{*}{ SEM } & \multirow[b]{2}{*}{$P$-value } \\
\hline & Revalor-IH & Synovex-H & & \\
\hline Hot carcass weight, kg & 359 & 355 & 2 & 0.15 \\
\hline Dressing percentage & 65.2 & 65.5 & 0.1 & 0.23 \\
\hline 12th-rib fat, $\mathrm{cm}$ & 1.34 & 1.32 & 0.05 & 0.60 \\
\hline Empty body fat, $2 \%$ & 29.4 & 29.0 & 0.2 & 0.12 \\
\hline LM area, $\mathrm{cm}^{2}$ & 91.0 & 92.3 & 0.7 & 0.26 \\
\hline Dark cutters, \% & 1.12 & 2.73 & 0.87 & 0.14 \\
\hline Marbling score ${ }^{3}$ & 552 & 533 & 8 & 0.07 \\
\hline \multicolumn{5}{|l|}{ USDA QG, \% } \\
\hline Prime & 1.4 & 1.1 & 0.6 & 0.74 \\
\hline Upper 2/3 Choice & 23.6 & 14.9 & 2.5 & 0.02 \\
\hline Low Choice & 43.7 & 50.4 & 3.3 & 0.11 \\
\hline Select & 30.4 & 32.8 & 2.9 & 0.55 \\
\hline Standard & 0.9 & 0.8 & 0.52 & 0.87 \\
\hline$\geq$ Choice carcasses & 68.7 & 66.4 & 2.9 & 0.59 \\
\hline \multicolumn{5}{|l|}{ USDA YG, \% } \\
\hline 1 & 5.0 & 5.4 & 1.0 & 0.64 \\
\hline 2 & 28.3 & 29.8 & 3.5 & 0.62 \\
\hline 3 & 51.9 & 46.4 & 2.9 & 0.16 \\
\hline 4 & 14.4 & 17.0 & 2.7 & 0.37 \\
\hline 5 & 0.4 & 1.4 & 0.5 & 0.15 \\
\hline Calculated $Y^{4}$ & 2.71 & 2.60 & 0.06 & 0.09 \\
\hline
\end{tabular}

${ }^{1}$ All heifers implanted with Revalor-200 (Intervet/Schering Plough Animal Health, DeSoto, KS) as the common terminal implant. Revalor-IH was from Intervet/Schering Plough Animal Health, and Synovex-H was from Fort Dodge Animal Health (Overland Park, KS).

${ }^{2}$ Calculated from Guiroy et al. (2002), where empty body fat $=17.76207+(4.68142 \times$ 12th-rib fat thickness $)+(0.01945 \times$ hot carcass weight $)+(0.81855 \times \mathrm{QG})-(0.06754$ $\times$ LM area).

${ }^{3}$ Marbling score: $450=$ Slight ${ }^{50} ; 500=$ Small $^{0} ; 550=$ Small ${ }^{50} ; 600=$ Modest $^{0} ;$ etc . ${ }^{4}$ Calculation from American Meat Science Association (2001).

lication were marketed on a common day under identical conditions at the same commercial abattoir (National Beef Packing, Dodge City, KS). In Exp. 2, carcass data were collected in a manner similar to that described in Exp. 1.

Animal performance and carcass data were analyzed using the MIXED procedure of SAS (SAS Institute Inc., Cary, NC) for a randomized complete block design, where pen served as the experimental unit. Chi-square distribution analysis was used for QG and YG data. The fixed model effect included the initial implant treatment, and replication of cattle was termed a blocking factor and placed into the random statement. Least squares means were separated using the PDIFF statement of SAS.

\section{RESULTS AND DISCUSSION}

All data are presented with dead animals and railers (cattle that are sold prior to being finished because of illness or an injury) removed from the analysis. As a result, in Exp. 1, 28 and 15 heifers were removed from the Revalor-IH and Synovex-H treatments, respectively. In Exp. 2, 15 and 13 steers were removed from the Revalor-IS and Synovex-S treatments, respectively. Feed intake was calculated from feedlot close-out information on each individual pen of cattle. Defects in the initial implants
(Exp. 1), as determined at the time of reimplantation, are summarized in Table 2. Initial implants were checked for determination of abscessed, missing, crushed, or cartilage placed implants (Table 2). Only 1.6\% of heifers administered Revalor-IH and $2.2 \%$ of heifers administered Synovex$\mathrm{H}$ were found to have implants that fell within these criteria. In Exp. 2, only 1 animal in the Revalor-IS and 3 animals in the Synovex-S treatments possessed abscessed implants. Additionally, only 13 animals in the Revalor-IS and 15 in the Synovex-S treatment had identifiable defects in the initial implant. Therefore, $2.5 \%$ of steers administered Revalor-IS and $2.8 \%$ of steers administered Synovex-S were found to have implants that fell within the defective criteria.

Heifer performance is presented in Table 3 and is expressed on a live performance basis and on a carcassadjusted basis using a common dressing percentage $(63 \%)$. Dry matter intake was similar between treatments $(P=0.63)$. On a carcass-adjusted basis, heifers implanted initially with Revalor-IH tended $(P=0.10)$ to have greater ADG and greater G:F $(P=0.03)$ compared with heifers given Synovex-H. Likewise, on a live basis, heifers implanted initially with Revalor-IH tended $(P=0.05)$ to gain faster and had increased G:F $(P=$ 0.01). Revalor-IH-implanted heifers tended to have heavier $(P=0.15)$ HCW but similar dressing percentage, 12th-rib fat thickness, and LM area when compared with Synovex-H-implanted heifers (Table 4). Calculated empty body fat and USDA called YG were similar between treatments, indicating that heifers were fed to similar body fat end points. Calculated YG tended $(P=0.09)$ to be higher for heifers implanted with Revalor-IH (2.71 vs. 2.60 for Revalor-IH and Synovex-H, respectively) as a result of heavier HCW used in the calculation. Total carcasses grading Choice were not different between initial implant treatments. However, heifers administered Revalor-IH had greater $(P=$ 0.07 ) marbling scores, with $58 \%$ more carcasses $(P=0.02)$ achieving the up- 


\section{Table 5. Effects of Revalor-IS or Synovex-S as initial implants on feedlot steer performance (Exp. 2)}

\begin{tabular}{lcccc} 
& \multicolumn{2}{c}{ Initial implant $^{1}$} & & \\
\cline { 2 - 3 } Item & Revalor-IS & Synovex-S & SEM & $P$-value \\
\hline Number of pens & 6 & 6 & - & - \\
Number of steers & 518 & 520 & - & - \\
Initial BW, kg & 269 & 269 & 2.0 & 0.80 \\
DMl, kg & 9.1 & 9.2 & 0.14 & 0.45 \\
Carcass performance & & & & \\
Final BW, ${ }^{2}$ kg & 576 & 572 & 1.6 & 0.07 \\
ADG ${ }^{3}$ kg & 1.71 & 1.69 & 0.02 & 0.22 \\
G:F & 0.188 & 0.183 & 0.003 & 0.24 \\
Live performance & & & & \\
Final BW, ${ }^{3}$ kg & 570 & 568 & 1.5 & 0.20 \\
ADG, ${ }^{5}$ kg & 1.68 & 1.66 & 0.01 & 0.31 \\
G:F & 0.185 & 0.181 & 0.003 & 0.30 \\
\hline
\end{tabular}

${ }^{1}$ All steers implanted with Revalor-S (Intervet/Schering Plough Animal Health, DeSoto, KS) as the common terminal implant. Revalor-IS was from Intervet/Schering Plough Animal Health, and Synovex-S was from Fort Dodge Animal Health (Overland Park, KS).

${ }^{2}$ Calculated as hot carcass weight $\div 0.63$ (common dressing percentage).

${ }^{3}$ Calculated using carcass-adjusted final weight.

${ }^{4}$ Calculated from live pen weights and shrunk $4 \%$.

${ }^{5}$ Calculated from live final BW.

per two-thirds category of Choice QG (Table 4).

Feedlot performance of steers (Exp. 2 ) is presented in Table 5 and is expressed on a live and carcass-adjusted basis using a common dressing percentage (63\%). Dry matter intake was similar between treatments. Steers implanted initially with Revalor-IS had $3.6 \mathrm{~kg}$ greater $(P=0.07)$ carcass-adjusted final BW compared with steers initially implanted with Synovex-S. Although implanting steers initially with Revalor-IS improved G:F by $2 \%$ in the live category and $2.5 \%$ in the carcass-adjusted calculation, neither difference was significantly different from the Synovex-S treatment $(P=$ 0.30 and 0.23 , respectively). Similarly, live ADG $(P=0.31)$ and carcassadjusted ADG $(P=0.22)$ were not different between implant treatments.

Carcass characteristics for Exp. 2 are shown in Table 6. Steers implanted with Revalor-IS had $2.3 \mathrm{~kg}$ heavier $(P=0.07) \mathrm{HCW}$ but similar dressing percentage, 12 th-rib fat thickness, calculated empty body fat, and LM area when compared with steers implanted with Synovex-S. The USDA called YG and calculated YG were similar between treatments, indicating that steers were fed to a similar compositional end point. Marbling scores, carcasses grading upper two-thirds Choice, and total carcasses grading Choice were not different between initial implant treatments. Yield grade breakdowns are also presented in Table 6 . There were no differences between treatments when analyzed in single numerical categories or when combined, as was illustrated when YG 1 and 2 were combined.

Although the anabolic response of ruminants to exogenous androgens and estrogens is still not thoroughly understood, it has been well established that growth promotants increase the rate of protein deposition in feedlot cattle by stimulating skeletal muscle growth. Cattle given combinations of TA and E2 have been observed to gain faster compared with cattle that are given E2 or TA alone (Bartle et al., 1992; Johnson et al.,
1996). Typically, cattle are initially implanted with an estrogen-based implant at the beginning of the feeding period and then reimplanted with an E2-TA combination implant.

Revalor-IS and Revalor-IH are considered mild combination implants (Montgomery et al., 2001). Limited data are available comparing these relatively new mild combination initial E2-TA implants with estrogenbased initial implants. Data from Hutcheson et al. (2003) suggest that a single implant of a combination of E2 and TA, used in either the full or reduced-dosage form, increased ADG, G:F, and $\mathrm{HCW}$ while maintaining carcass quality in short-fed yearling steers when compared with an estrogen-based, single implant program.

Data from Exp. 1 provide evidence that Revalor-IH as an initial implant for feedlot heifers leads to equal or better performance when compared with estrogen-based initial implants (Synovex-H) and improves marbling and carcasses grading high Choice. The primary difference in hormone composition of the 2 initial implant treatments is the presence of $80 \mathrm{mg}$ TA in the Revalor-IH, but another notable difference is the lower E2 content of Revalor-IH compared with Synovex-H (8 vs. $14.4 \mathrm{mg}$ ). In heifers, MGA prevents ovulation and increases estrogenic secretion by persistent follicles (Bloss et al., 1966). Therefore, only part of the exogenous estrogen from the initial implants was needed to stimulate skeletal muscle growth and improve G:F. This suggests that differences in response between initial implant treatments for feedlot heifers may be due to the effects of TA.

Data from Exp. 2 illustrate similar effects on performance or carcass characteristics when implanting steers initially with Revalor-IS or SynovexS. However, Revalor-IS tended to improve HCW and carcass-adjusted final BW compared with steers implanted initially with Synovex-S. Hutcheson and Larson (2005) evaluated the performance of 2,578 beef feedlot steers in 2 large pen trials with the same experimental design used in the present study. Steers were initially implanted 


\section{Table 6. Effects of Revalor-IS or Synovex-S as initial implants on carcass characteristics of finishing steers (Exp. 2)}

\begin{tabular}{|c|c|c|c|c|}
\hline \multirow[b]{2}{*}{ Item } & \multicolumn{2}{|c|}{ Initial implant ${ }^{1}$} & \multirow[b]{2}{*}{ SEM } & \multirow[b]{2}{*}{$P$-value } \\
\hline & Revalor-IS & Synovex-S & & \\
\hline Hot carcass weight, kg & 363 & 361 & 1.02 & 0.07 \\
\hline Dressing percentage & 63.6 & 63.4 & 0.12 & 0.26 \\
\hline 12th-rib fat, $\mathrm{cm}$. & 1.22 & 1.22 & 0.13 & 1.00 \\
\hline Empty body fat, $2 \%$ & 28.8 & 28.8 & 0.14 & 0.74 \\
\hline LM area, $\mathrm{cm}^{2}$ & 87.7 & 87.1 & 0.71 & 0.24 \\
\hline Dark cutters, \% & 1.12 & 2.73 & 0.87 & 0.14 \\
\hline Marbling score ${ }^{3}$ & 516 & 516 & 4.34 & 0.97 \\
\hline \multicolumn{5}{|l|}{ USDA QG, \% } \\
\hline Prime & 1.2 & 0.2 & 0.51 & 0.11 \\
\hline Upper 2/3 Choice & 18.8 & 19.8 & 3.14 & 0.76 \\
\hline Low Choice & 36.8 & 39.2 & 2.06 & 0.31 \\
\hline Select & 40.7 & 38.8 & 1.1 & 0.14 \\
\hline Standard & 2.5 & 2.0 & 1.38 & 0.73 \\
\hline Total Choice carcasses, \% & 55.6 & 58.2 & 1.36 & 0.15 \\
\hline \multicolumn{5}{|l|}{ USDA YG, \% } \\
\hline 1 & 7.6 & 8.3 & 0.99 & 0.53 \\
\hline 2 & 52.8 & 46.5 & 4.26 & 0.20 \\
\hline 3 & 32.5 & 39.4 & 5.59 & 0.28 \\
\hline 4 & 6.0 & 4.8 & 1.1 & 0.35 \\
\hline 5 & 1.1 & 1.0 & 0.7 & 0.82 \\
\hline Calculated $\mathrm{YG}^{4}$ & 2.9 & 2.9 & 0.04 & 0.37 \\
\hline
\end{tabular}

${ }^{1}$ All steers implanted with Revalor-S (Intervet/Schering Plough Animal Health, DeSoto, KS) as the common terminal implant. Revalor-IS was from Intervet/Schering Plough Animal Health, and Synovex-S was from Fort Dodge Animal Health (Overland Park, KS).

${ }^{2}$ Calculated from Guiroy et al. (2002), where empty body fat $=17.76207+(4.68142 \times$ 12th-rib fat thickness $)+(0.01945 \times$ hot carcass weight $)+(0.81855 \times \mathrm{QG})-(0.06754$ $\times$ LM area).

${ }^{3}$ Marbling score: $450=$ Slight $^{50} ; 500=$ Small $^{0} ; 550=$ Small ${ }^{50} ; 600=$ Modest $^{0} ;$ etc.

${ }^{4}$ Calculation from American Meat Science Association (2001).

with Synovex-S and Revalor-IS and reimplanted with Revalor-S on approximately d 80 . No differences were detected between initial implants for performance and carcass characteristics. Hutcheson and Larson (2005) observed that either Synovex-S or Revalor-IS, when used as an initial implant in a reimplantation program, would result in similar feedlot performance and carcass characteristics of yearling steers. These results are in agreement with data from the present study and suggest that initial implant programs using mild combinations will have no negative effects on performance or carcass characteristics of finishing steers.

These data suggest that reduceddose combinations of E2 and TA can be used effectively as initial implants for feedlot cattle. No negative effects of these implants on performance or carcass characteristics of finished cattle were observed. In addition, these experiments demonstrate a significant increase in feed efficiency and carcass quality in finishing heifers and a possible increase in carcass weight in finishing steers when moderate-dose E2-TA implants replace estrogenbased initial implants.

\section{LITERATURE CITED}

American Meat Science Association. 2001. Meat Evaluation Handbook. Am. Meat Sci. Assoc., Savoy, IL.

Bartle, S. J., R. L. Preston, R. E. Brown, and R. J. Grant. 1992. Trenbolone acetate/ estradiol combinations in feedlot steers:

Dose-response and implant carrier effects. J. Anim. Sci. 70:1326.

Bloss, R. E., J. I. Northam, L. W. Smith. and R. G. Zimbelman. 1966. Effects of oral melengestrol acetate on the performance of feedlot cattle. J. Anim. Sci. 25:1048.

Guiroy, P. J., L. O. Tedeschi, D. G. Fox, and J. P. Hutcheson. 2002. The effects of implant strategy on finished body weight of beef cattle. J. Anim. Sci. 80:1791.

Hutcheson, J. P., and E. Larson. 2005. Effects of initial implant strategies (Synovex-S versus Revalor-IS) on feedyard performance and carcass characteristics of yearling steers. Texas Tech Univ. North American Trenbolone Acetate Implant Database. http://www. depts.ttu.edu/afs/implantdb/dbhome/pdf/ multiple/s/163.pdf Accessed April 15, 2009.

Hutcheson, J. P., C. D. Reinhardt, G. E. Sides, and W. T. Nichols. 2003. Evaluation of Revalor-IS, Revalor-S, and Component-ES on performance and carcass merit of short-fed finishing steers. J. Anim. Sci. 81(Suppl. 1):112. (Abstr.)

Johnson, B. J., P. T. Anderson, J. C. Meiske, and W. R. Dayton. 1996. Effect of a combined trenbolone acetate and estradiol implant on steroid hormone levels, feedlot performance, carcass characteristics and carcass composition of feedlot steers. J. Anim. Sci. 74:363

Montgomery, T. H., P. F. Dew, and M. S. Brown. 2001. Optimizing carcass value and the use of anabolic implants in beef cattle. J. Anim. Sci. 79(E Suppl.):E296.

NRC. 1996. Nutrient Requirements of Beef Cattle. 7th ed. Natl. Acad. Press, Washington, DC.

Preston, R. L., S. J. Bartle, A. C. Brake, and R. E. Castlebury. 1990. Effect of anabolic growth implants on the time required to reach quality grade equivalent to non-implanted cattle. Texas Tech Univ. Agric Sci. Tech. Rep. No. T-5-283. Texas Tech. Univ., Lubbock. 